\title{
レーザー光を用いた生体硬組織複合材料の開発
}

\author{
松谷 貴臣、熊㟝 建二、中山 斌義、久保 宇市
}

近畿大学 理工学部 電気工学科

\section{Development of biocompatible composite material using laser irradiation method}

\author{
Takaomi MATSUTANI, Kenji KUMAZAKI, Takeyoshi NAKAYAMA, and Uichi KUBO \\ Department of Electrical Engineering, Faculty of Science and Technology, Kinki University
}

\begin{abstract}
In order to obtain a biocompatibility of an alumina $\left(\mathrm{Al}_{2} \mathrm{O}_{3}\right)$ ceramics, a hydroxyapatite (HAp) layer on the surface has been formed by $\mathrm{KrF}$ excimer laser irradiation. The biocompatibility of $\mathrm{HAp} / \mathrm{Al}_{2} \mathrm{O}_{3}$ composite material has been confirmed in vitro. An apatite - wollastonite glass (A-W glass) and a simulated body fluid (SBF) have been used as a substitute of a bone and a human blood plasma, respectively. The $\mathrm{HAp} / \mathrm{Al}_{2} \mathrm{O}_{3}$ sample which is faced to A-W glass was immersed into SBF keeping at $36.5^{\circ} \mathrm{C}$ and $\mathrm{pH} 7.2$. In the case of sample immersed for 2 weeks, morphological change on the $\mathrm{HAp} / \mathrm{Al}_{2} \mathrm{O}_{3}$ surface was observed by an electron probe microanalyzer (EPMA). An X-ray diffraction (XRD) pattern was indicated that a bone-like apatite was formed on the $\mathrm{HAp} / \mathrm{Al}_{2} \mathrm{O}_{3}$ surface. From these results, it is considered that $\mathrm{HAp} / \mathrm{Al}_{2} \mathrm{O}_{3}$ composite material formed by $\mathrm{KrF}$ excimer laser irradiation has a good biocompatibility.
\end{abstract}

1.はじめに

医療用セラミックスとして用いられているアル ミナ $\left[\mathrm{Al}_{2} \mathrm{O}_{3}\right]$ は、他のセラミックスに比べ高強度、 耐摩耗性に優れている等の特徴から、負荷の大き い人工関節や人工歯根等に古くから用いられてい る1。しかし、生体に対して不活性であるため、 生体との接合には、ねじ切り等の機械的な接合が
必要であった。一方、骨の無機成分と同じ構造を 持つハイドロキシアパタイト [HAp： $\left.\mathrm{Ca}_{10}\left(\mathrm{PO}_{4}\right)_{6}(\mathrm{OH})_{2}\right]$ は、生体と化学的に結合する生体 親和性材料として知られている 。近年、HAp 自 身では機械的強度に欠けるため各母材の表面に付 加し、生体となじみのある複合材料の研究が各種

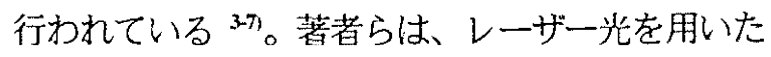


$\mathrm{HAp} / \mathrm{Al}_{2} \mathrm{O}_{3}$ 複合材料の開発を試み、 $\mathrm{Al}_{2} \mathrm{O}_{3}$ 表面へ密 着性が高く、結晶性に優れた HAp 層の形成に成功 している \%の。本報告は、その作製した試料の生体 親和性の有無を確認するため擬似生体液 (Simulated Body Fluid: SBF)を用いた生体外試験（in vitro) を行ったものである。

\section{2. 実験方法}

\section{$2.1 \mathrm{HAp} / \mathrm{Al}_{2} \mathrm{O}_{3}$ 複合材料の作製}

紫外光に対して透明な $\mathrm{Al}_{2} \mathrm{O}_{3}$ を $\mathrm{HAp}$ に密着さ せ $\mathrm{Al}_{2} \mathrm{O}_{3}$ 側から $\mathrm{KrF}$ エキシマレーザー $(\lambda=248 \mathrm{~nm}$, $\tau=23 \mathrm{nsec}$ )を 400 回照射した。照射条件は、照射 フルエンス $0.7 \mathrm{~J} / \mathrm{cm}^{2} \cdot$ pulse, 繰り返し周波数 $2 \mathrm{~Hz}$ で ある。レーザ一照射後、 $\mathrm{HAp}$ と $\mathrm{Al}_{2} \mathrm{O}_{3}$ の密着性を 確認するため脱イオン水中にて 10 分間超音波洗浄 を行った。その後、電子線プローブマイクロアナ ライザー (EPMA) を用いて作製した試料の形状観 察及び成分分析を行った。Fig. 1 (a) は作製した試 料の断面写真を示す。この断面写真と同位置に対 応したX 線ラインプロファイルを Fig. 1 (b) に示す。

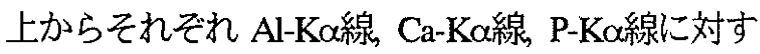

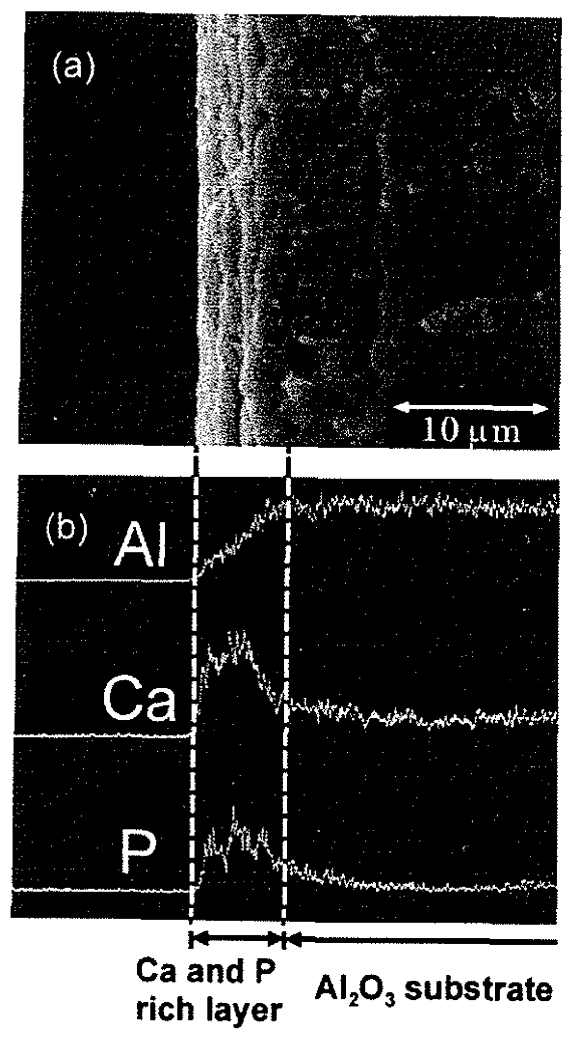

Fig. 1 EPMA observation of (a) cross-sectional view and (b) X-ray line profiles of laser irradiated sample.
る X 線の強度を示している。表面 (図中左) から 媣さ方向（図中右方向）に約 3-5 $\mu \mathrm{m}$ 程度まで Ca$\mathrm{K} \alpha$ 線及び $\mathrm{P}-\mathrm{K} \alpha$ 線の強度力強くなっている。即ち、 $\mathrm{Al}_{2} \mathrm{O}_{3}$ 表面に $\mathrm{Ca}$ と $\mathrm{P}$ のリッチ層力形成されている 事が判る。この層の $\mathrm{Ca} / \mathrm{P}$ 比を測定した結果、 $\mathrm{HAp}$ と同様 1.67 を示した。また光電子分光法、電子線 回折等の評価から熱変性の少ない、結晶性に優れ た HAp 層である事か確認された。

\section{2 in vitro による生体親和性確忍}

作製した試料の生体親和性を確認するため in vitro 試験を行った ${ }^{3)}$ 。その実験概略図を Fig. 2 に示 す。生体内と同条件の環境を作り出すため、血墏 の代わりにSBF、骨の代用として apatite - wollastonite glass (A-W glass)を用いた。A-W glass は、試料の石 灰化に必要な $\mathrm{Ca}$ イオン及び $\mathrm{P}$ イオンを骨同様に 生体液中で溶出し、それらを過飽和の状態に維持 するためのものである。

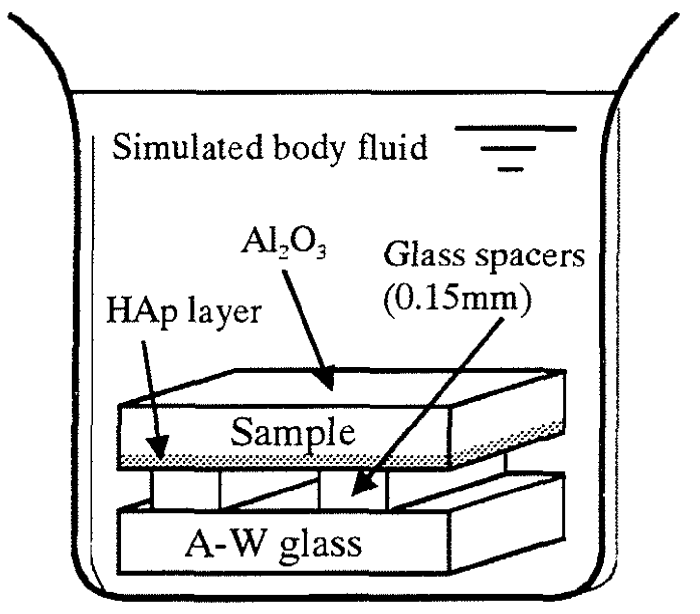

Fig. 2 Biocompatibility confirmation of $\mathrm{HAp} / \mathrm{Al}_{2} \mathrm{O}_{3}$ composite material using $\mathrm{A}-\mathrm{W}$ glass and $\mathrm{SBF}$.

Table 1 Component ratio of A-W glass (wt\%).

\begin{tabular}{cccccc}
\hline Element & $\mathrm{MgO}$ & $\mathrm{CaO}$ & $\mathrm{SiO}_{2}$ & $\mathrm{P}_{2} \mathrm{O}_{5}$ & $\mathrm{CaF}_{2}$ \\
\hline $\begin{array}{c}\text { Component ratio } \\
\text { (wt\%) }\end{array}$ & 4.6 & 44.7 & 34.0 & 16.2 & 0.5 \\
\hline
\end{tabular}

本実験で用いた A-W glass は、Table 1 に示す各 成分の重量比で粉末を調合した。錠剤形成器によ つて加圧整形した後、その錠剤を $700{ }^{\circ} \mathrm{C} て ゙ 5$ 時間、 アニールを行ったものを使用した。

SBFは $\mathrm{NaCl}, \mathrm{NaHCO}_{3}, \mathrm{KCl}, \mathrm{K}_{2} \mathrm{HPO}_{4}, \mathrm{MgCl}_{2} 6 \mathrm{H}_{2} \mathrm{O}$, $\mathrm{CaCl}$ ，及び $\mathrm{Na}_{2} \mathrm{SO}_{4}$ を蒸留水に溶解して、血漿のイ 

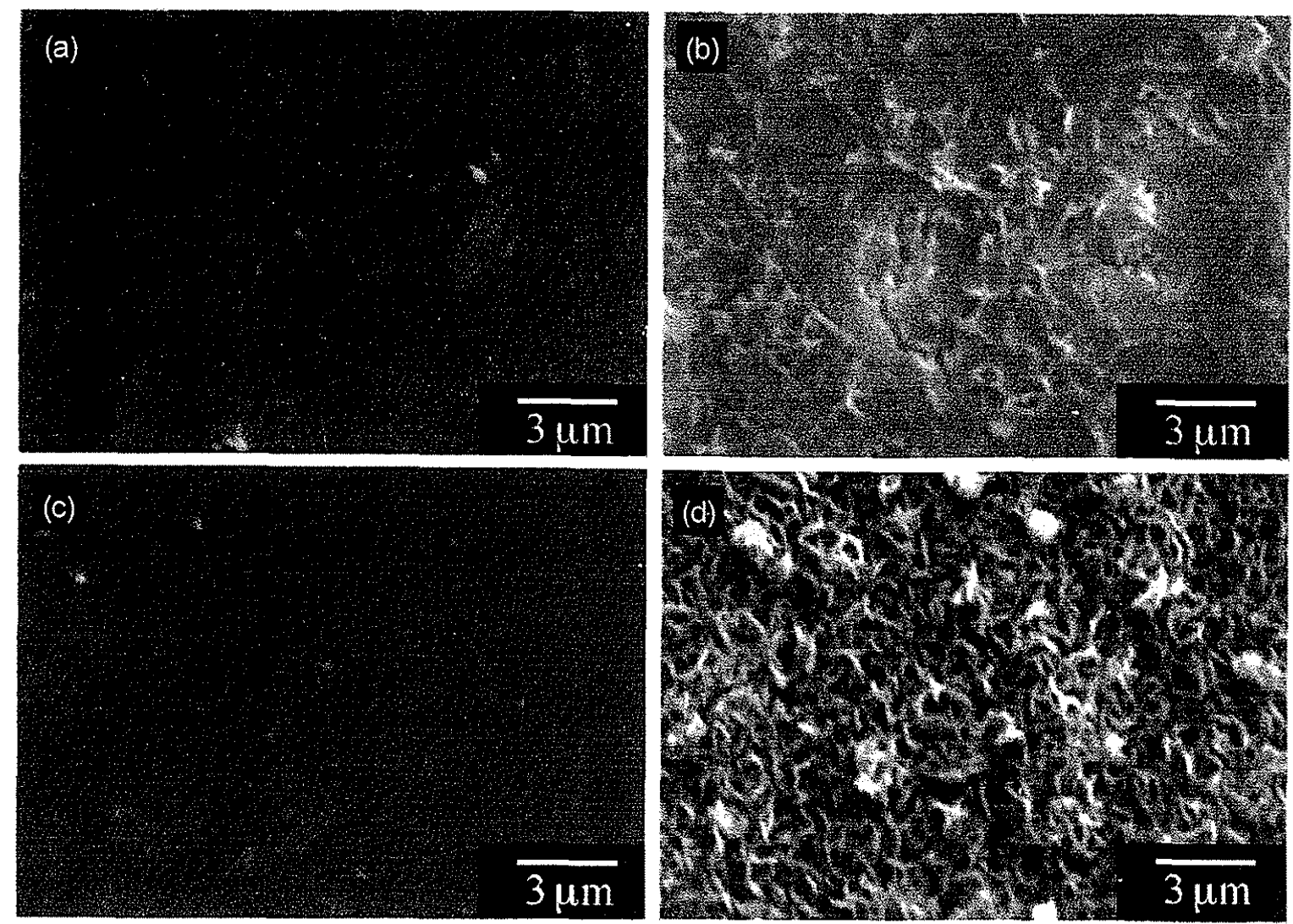

Fig. 3 SEM images of sample surface after immersion into SBF. (a) unirradiated and (b) laser irradiated sample soaked for 2 days. (c) unirradiated and (d) laser irradiated sample soaked for 2 weeks.

オン濃度に近いものを作製した。SBF 及び血墏中 のイオン濃度を Table 2に示す。上記以外に緩衝薬 としてトリアミノメタン $\left[\left(\mathrm{CH}_{2} \mathrm{OH}\right)_{3} \mathrm{CNH}_{2}\right]$ を用い $\mathrm{pH} 7.3$ に維持するために HCl $45 \mathrm{mM}$ 潞加した。 本実験では、石灰化の促進を図るためSBF のイオ ン濃度を2 倍にして用いた。

作製した試料の HAp 層表面と $\mathrm{A}-\mathrm{W}$ glass を厚 さ $0.15 \mathrm{~mm}$ のスペーサーを介して密接させ、体温 近くの $36.5{ }^{\circ} \mathrm{C}$ に保持した SBF 中に、2 日間及び 2 週間浸漬させた。浸漬後の試料表面を脱イオン水 中で超音波洗浄を 5 分間行い、EPMA を用いて表 面の形状観察及び成分分析を行った。また、結晶 性の確認には、Cu-X $\alpha(\lambda=0.154 \mathrm{~nm})$ を線源とす るX 線回折 $(\mathrm{XRD})$ 装置を使用した。

\section{3. 実験結果及び考察}

レーザー照射によって作製した $\mathrm{HAp} / \mathrm{Al}_{2} \mathrm{O}_{3}$ 複合 材料の生体親和性を確認するため A-W glass と共 に SBF 中に浸漬した。Fig. 3 (a)，(b) はそれぞれ2 日間浸漬後のレーザー未照射部分 $\left(\mathrm{Al}_{2} \mathrm{O}_{3}\right.$ 表面 $)$ 、
Table 2 Ion concentration of SBF (mM).

\begin{tabular}{lrr}
\hline Ion & SBF & $\begin{array}{r}\text { Blood } \\
\text { plasma }\end{array}$ \\
\hline $\mathrm{Na}^{+}$ & 142.0 & 142.0 \\
$\mathrm{~K}^{+}$ & 5.0 & 5.0 \\
$\mathrm{Ca}^{+}$ & 2.5 & 2.5 \\
$\mathrm{Mg}^{+}$ & 1.5 & 1.5 \\
$\mathrm{Cl}^{-}$ & 147.8 & 103.0 \\
$\mathrm{HCO}_{3}{ }^{-}$ & 4.2 & 27.0 \\
$\mathrm{HSO}_{4}{ }^{2-}$ & 1.0 & 1.0 \\
$\mathrm{SO}_{4}{ }^{2-}$ & 0.5 & 0.5 \\
\hline
\end{tabular}

レーザー照射部分（HAp 層表面）の表面写真であ る。 $\mathrm{Al}_{2} \mathrm{O}_{3}$ 表面は非常にフラットな面であるのに対 し、HAp 表面には凹凸が見られ，若干の繊維状の 物質か形成している。さらに Fig. 3 (d) 2 週間浸漬 後の HAp 層表面では、その物質が成長している事 が判る。これは KKurashina らの報告した、SBFを 用いた in vitro によって燐酸力ルシウムセメント (calcium phosphate cement) 上に成長した HAp の形状 によく似ている10。一方、Fig. 3(c) に見られる様に 


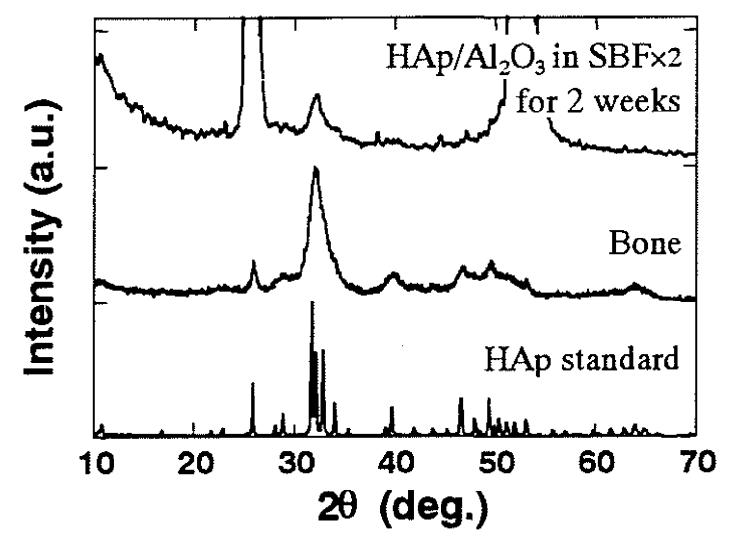

Fig. 4 XRD pattern of $\mathrm{HAp} / \mathrm{Al}_{2} \mathrm{O}_{3}$ soaked in $\mathrm{SBF}$ for 2 weeks (upper line), bone (middle line) and HAp standard sample (lower line).

$\mathrm{Al}_{2} \mathrm{O}_{3}$ 表面には 2 週間浸漬後でも全く変化が無い。 これは、 $\mathrm{Al}_{2} \mathrm{O}_{3}$ が生体に対して不活性である事を示 唆している。

SBF 中に浸漬する事によって成長した繊維状 の物質を調べるため XRD を用いた。Fig. 4 は、上 段に SBF 浸漬後 2 週間の試料、中段及ひ下段は比 較のため牛大腿部の皮質骨、 $\mathrm{HAp}$ 標準試料の XRD スペクトルである。SBF 浸漬後の試料から $25^{\circ} 32^{\circ}$ 及び $52^{\circ}$ 付近にピークを示した。 $25^{\circ}$ 及び $52^{\circ}$ のピ 一クはそれぞれ $\mathrm{Al}_{2} \mathrm{O}_{3}$ の (012), 及び (024)面からの

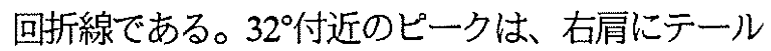
を引いており、その強度比から比較すると HAp の (211), (112), 及び (300) 面に対応している。EPMA を用いて各表面の $\mathrm{Ca} / \mathrm{P}$ 比を比較を行つた結果、SBF 浸漬後の試料表面、皮質骨及び HAp 標準試料はそ れぞれ $1.596,1.549$, 及び 1.667 を示した。浸漬前の 試料表面より $\mathrm{P}$ リッチな膜になっており、皮質骨 の Ca/P 比に近い値になっている。また皮質骨と類 似した XRD スペクトルを示している事から、縉維 状の物質は新生骨を示唆する骨様アパタイトであ ると判断できる。以上の結果から、レーザ一光照 射によって作製した $\mathrm{HAp} / \mathrm{Al}_{2} \mathrm{O}_{3}$ 複合材料は、生体 親和性に優れている事が判った。

\section{4. まとめ}

$\mathrm{KrF}$ エキシマレーザーを用いて作製した $\mathrm{HAp} / \mathrm{Al}_{2} \mathrm{O}_{3}$ 複合材料の生体親和性の有無について
SBF を用いた in vitro 試験を行った。骨の代わりに 用いた A-W glass と作製した試料を $0.15 \mathrm{~mm}$ のス ペーサーを介して密接させ、血墏中のイオン濃度 に対し 2 倍の SBF 中に 2 週間浸漬させた。その結 果、未照射部の $\mathrm{Al}_{2} \mathrm{O}_{3}$ 上には変化が生じなかった のに対し、レーザ一照射によって $\mathrm{Al}_{2} \mathrm{O}_{3}$ 上に形成 した HAp 層表面には、緎維状の物質が新たに形成 されていた。その物質を評価した結果、結晶構造 及び $\mathrm{Ca} / \mathrm{P}$ 比共に、骨に類似したアパタイトが再形 成されている事が判った。以上の事から、レーザ 一照射によって作製した $\mathrm{HAp} / \mathrm{Al}_{2} \mathrm{O}_{3}$ 複合材料の生 体親和性向上が認められた。

本研究怯、平成 7 年度文部省科学研究費補助金 （一般研究 B ・研究課題番号 07455296）によってな されたものである。

1)日本機㧔学会: 生体材料学（オ一公社，1993）100

2) 片岡 一則 : 生命材料工学 (裳華房, 1991) 104

3) Y. ABE, T. KOKUBO and T. YAMAMURO : J. Mater. Sci. Mater. Med. 1(1990) 233

4) HUAXIA JL, C. B. PONTON and P. M.MARQUIS : J. Mater. Sci. Mater. Med. 3(1992) 283

5) M. YOSHINARI, Y. OHTSUKA and T. DÉRAND : Biomaterials 15 (1994) 529

๑) R. K. SINGH. F. QIAN, V. NAGABUSHNAM, R. DAMODARAN and B.M.MOUDGLL : Biomaterials 15 (1994) 522

7) M. SHRRKHANZADEH : J. Mater. Sci. Mater. Med 6(1995) 90

8) 松谷 貴臣、熊崎 建二、中山 斌義、久保 宇市: 第 16 回日本レーザー医学会大会論文集 (1990) 325

9）熊㟝 建二 松谷 貴臣、中山 斌義、久保 宇市: 近畿大 学理工学部研究報告 (1996) 55

10) K. KURASHINA, H. KURTTA, M. HIRANO, J. M. A. de BLIECK, C. P. A T. KIEIN and K de GROOT: J. Mater. Sci. Mater. Med. $6(1995) 342$ 